\title{
ASSIS, Valesca de. A ponta do silêncio. Porto Alegre: BesouroBox, 2016. $88 \mathrm{p}$.
}

A professora Marga Treibel encontra-se internada em um hospital. Depois do acontecido entre ela e o marido, não consegue pronunciar nenhuma palavra. O motivo? É acusada de ter matado o companheiro, Rudy Treibel, após trinta e três anos de casamento. Não há certezas do crime cometido pela professora, mas as evidências a acusam: ela levou o marido ao atendimento médico, ele, com marcas de várias facadas pelo corpo; ela, com o sangue do marido em suas roupas. E a impossibilidade de explicar sobre o ocorrido.

É esse o mote do novo romance de Valesca de Assis. Publicada em 2016 pela BesouroBox, a narrativa, de pouco mais que 80 páginas, é intensa, sensível e tem como tema um problema cotidiano muito conhecido do público feminino: até que ponto você castiga a sua vida, seus sentimentos e suas vontades em nome do seu companheiro.

O delegado Leonel tem a tarefa de descobrir o que de fato aconteceu no assassinato de Rudy Treibel. Marga, a esposa, foi sua professora no colégio, assim como a metade dos jovens da cidade de Cruzeiro. Tem carinho pela pessoa à sua frente, uma velhinha aparentemente indefesa, mas que pode ser a assassina do homem com quem viveu por mais de trinta anos.

A impossibilidade de falar sobre o fato é compensada a Leonel e ao leitor pela organização escrita na qual a narrativa de Marga toma forma. No cuidado e no zelo com que o delegado tem para com a professora e a situação, devido à relação professor/aluno que tiveram no passado, Marga se sente mais à vontade para, além do choro compulsivo em que o descontrole lhe envolve, poder expressar, através da palavra escrita, o que realmente aconteceu ao marido, a ela, à família. Apesar do interlocutor não lhe exigir rapidez em seu depoimento, Marga lamenta que Leonel não saiba "do anel de fogo, do cativeiro das palavras" (p. 16) em que ela se encontra.

A sensibilidade da narrativa se mostra ao passo em que vamos descobrindo as ações de Marga. A primeira é a de se internar, em um hospital de freiras, e de receber pessoas, questionamentos e a medicação intravenosa. As sensações da protagonista vão se revelando e se mostrando alteradas com o ambiente externo. Tudo se mostra revirado, confuso; e o corpo, ao refletir essa confusão, não consegue dosar os impactos que as ações, as causas e as consequências tiveram até o presente momento. Por isso, sente frio: "muito frio. O tempo lá fora é quente: um dos verões mais tórridos dos últimos anos, as pessoas queixam-se. Em mim, o frio arrepia-me o corpo e a consciência ainda sombria do que fiz. Ou não fiz. Uma lembrança perdida na neblina" (p. 17).

Os posicionamentos dos moradores da cidade tomam a forma de juízes injustos, que não sabem do que de fato aconteceu, mas expressam opiniões vazias de sentido e cheias de acusações. A pergunta de todos, de o que levou uma mulher a cometer o crime de matar o marido, é esquecida diante de discursos preconceituosos e machistas, como se os problemas de um casamento não fossem suficientes diante à crueldade de uma mulher transtornada, porque só isso explicaria tal atitude. Mas há também uma representação de solidariedade feminina, como a mulher do delegado Leonel, Cirlene, e como a cunhada, Herta Treibel. Herta fala sobre o sofrimento de ser a primogênita numa família que desejava um homem como herdeiro. Já Cirlene, apesar de não ter sido aluna de Marga Treibel, admira o trabalho realizado pela professora em sua coluna no jornal. Nas visitas que faz à professora, no hospital, quer entender os motivos que levaram Marga a cometer o crime, e, num dos encontros, revela "eu compreendo, eu compreendo" (p. 64), "e chora, e seca os olhos com o lencinho branco" (p.64).

É a empregada da casa, "governanta, como seria chamada na família de Rudy" (p. 16), que leva os cadernos para que Marga possa escrever. A partir daí, "desde o acontecido, minha vida tem sido mediada pelo que vejo e ouço, e pelo que escrevo" (p. 19), e é através de cartas a Leonel que a história vai se organizando: "a ser verdade que o matei. Há instantes, o simples fato de escrever matei apavorou-me. Eu, no mais fundo de meus porões, jamais cogitaria a possibilidade de matar alguém" (p.25).

As cartas revelam, além da impossibilidade de falar, a necessidade da escrita. Há uma preocupação para que o seu leitor entenda os motivos que levam essa mulher a cometer tal ação, mas está presente, e talvez seja a questão mais importante, a tentativa de explicar a própria vida, e o quanto nossas decisões podem ser incompreendidas, o quanto podemos disfarçar nossas essências dentro de 
um comportamento considerado correto, o que pode desencadear uma tomada de mudança de um status quo, nem sempre esperado, mas que será, inevitavelmente, julgado por todos.

Marga vai contando nas cartas destinadas a Leonel o relacionamento abusivo em que vivia; Rudy era rico e de boa família, casou-se com Marga, deixando para trás uma namorada, "tão tristonha que talvez, se eu a tivesse conhecido, então, evitaria muitos dos meus sofrimentos matrimoniais, pois eu, com pena dela, não teria aceito a corte de Rudy" (p.34-35). A vida da professora, cheia de sonhos e de desejos de um futuro promissor através dos estudos, é interrompida pelo casamento com um bom partido, não resultado de uma paixão fulminante, pois "não foi um flechaço. Rudy não era um rapaz de amar-se à primeira vista" (p. 34), mas, talvez, uma mera decorrência de uma aceitação passiva.

Os primeiros anos de casamento anunciavam, aos poucos, a vida de substituição em que Marga viveria. Apesar de o princípio do matrimônio ser a união de dois corpos e de duas vidas em um mesmo lar, a constituir uma família, a protagonista percebe que, apesar de que "partilharíamos de uma aparente igualdade de espaços na casa e na família que iniciávamos" (p.49), a realidade do cotidiano se revelava oposta: "a cada dia, meu espaço e as marcas de minha presença diminuíam". Um objeto da família Trueba, colocado no lugar de um objeto que identificava esse novo casal, já revelava que aquela união estava comprometida a seguir uma tradição existente antes deles e de suas vontades, cabendo à estranha acatar.

Marga vai relembrando as inúmeras vezes em que suas marcas pessoais foram substituídas pelas marcas do marido, fosse através dos objetos trocados, fosse pelas agressões sofridas, pelas palavras ouvidas, enfim, pela própria vida, que era negligenciada em nome do outro. Nem sempre era negativo à primeira vista: "talvez pudesse dizer que tudo começou quando Rudy tirou do meu pescoço a fieira solitária de pérolas, e a substituiu por um colar de três voltas, fecho com diamantes e coral, tudo legitimo" (p.57), e, apesar de a substituição significasse o apagamento do que era, disfarçado por discursos de vida nova, para ela "foi um gesto amoroso, embora Rudy tenha jogado ao lixo o meu presente de quinze anos. Mas não posso dizer que não tenha gostado" (p.57). Pela beleza e pelo luxo possibilitados pelas posses do marido, Marga sempre se sentiu flor. O que foi mudando foram os sentidos dessa imagem: "aprisionada entre paredes, a flor torna-se inquieta, excessiva e doentia. Queimamse as pétalas, e o perfume torna-se nauseante, quase de velório" (p. 50).

A flor bela, mas murcha, é como um adorno na própria vida. Não é feita para a rua, como deseja, por imposição do casamento, do marido, das obrigações de esposa: é mais uma prisioneira pelo lar, pelas exigências em nome da família. Inquieta, torna-se, enfim, doente, porque não pode fugir dessa sua artificializada natureza.

Quando a filha engravidou do namorado, o "mau passo" (p.39) foi anunciado pela cunhada de Marga, e encarado muito negativamente pelo marido, apesar de esperada: "fúria, bebida, mais fúria e palavras sem medida" (p. 40). Ao tentar agredir a filha, a mãe se coloca diante de Vívian, e o marido acaba agredindo a esposa: "- Puta, sim, e tu és a culpada! - e ele me batia. - Essa mania de trabalhar fora, de abandonar as crianças... - e batia - ...soltas nas mãos das empregadas, aprendendo coisas ruins, fazendo coisas ruins" (p. 40).

A decadência nos negócios de Danúbio Azul, loja de tecidos da família Treibel, foi o passaporte para que Marga começasse sua independência financeira. As necessidades da família exigiram que trabalhasse com aulas particulares e, diante das oportunidades que foram surgindo, cursou mestrado e lecionou na universidade. A realidade decadente dos negócios da família do marido passou a estabelecer uma nova realidade para Marga: "foi quando percebi, de fato, que o mundo era bem maior que a minha casa, na rua Liberdade, e que ela, a liberdade, era bem mais que uma rua numa cidade pequena" (p.68). O apagamento da representação dessa mulher, no entanto, seguiu da mesma maneira: apesar de sustentar a casa e os filhos, o marido ainda era o centro daquele mundo, mesmo que a dignidade do alto padrão proporcionado pela loja da família fosse sendo, aos poucos, substituída pela impotência financeira e a bebida.

A doença do neto surge como uma nova dificuldade na família. Marga teme que a vida do menino seja curta e decide realizar uma festa para comemoração do natal e do aniversário do neto. A vinda da filha e da neta para a festa é tomada como afronta ao marido, mas Rudy acaba aceitando, em nome da boa aparência familiar na cidade. No entanto, não consegue se afastar da bebida, abusa e ofende a todos, tornando o momento em família em mais uma vergonha.

É quando ocorre o "crime". A neta entra na cozinha, o avô grita enfurecido, ofende a todas elas. Abre o robe e se mostra nu à neta pequena, que fecha os olhos, horrorizada. Vívian se arma de uma faca e vai contra o pai, mas Marga a empurra. Bêbado, Rudy grita ainda mais, e tenta ir sobre o corpo da mulher para provavelmente agredi-la. É quando escorrega na própria sujeira, cai no chão e bate a cabeça na quina do tanque, que escorria água: "e ele foi empalidecendo, escorregando, e, ao cair no lençol d'água, já era uma trouxa pesada e mole" (p.82).

Para Marga, nada mais importa, seja a morte do marido acidental ou não, seja as inúmeras facadas causadoras do assassinato ou não. A narrativa evidencia que a incompletude das palavras, novamente, revela 
os sentidos dos silêncios. Mesmo no relato produzido para se proteger, a personagem percebe que o silêncio deve ser desfeito como uma necessidade de ajustar as contas consigo mesma. Mais que a defesa de um crime de assassinato, é importante que Marga acerte as contas com a vida que se propôs a viver, pelo silêncio que ousou sustentar, sempre, diante dos desafios: "preciso erguer a ponta deste silêncio, erguer a ponta deste grande e solitário tapete urdido dia a dia em todos esses anos, e que é a coberta de minha vida".

$\mathrm{Na}$ cena inicial de $A$ ponta do silêncio, quando a menina, brincando com a boneca, no horário da sesta, acredita que o acidente fatal de bicicleta do amigo Marcos é apenas um sonho ruim, a descrição do ato pode passar despercebida ao leitor. Mas quando, anos depois, no relato de Marga sobre o acidente de moto que o ex-namorado da filha, também Marcos, sofre, enquanto observa a filha Vívian amamentando a neta, percebemos que a coincidência das duas cenas pode revelar algo mais importante que o indicado na primeira leitura, como uma sensação de déjà $v u$.

$\mathrm{O}$ leitor, talvez, volte às páginas iniciais e releia o capítulo "Depois do almoço". Encontra a cena já lida, mas, certamente, com mais riqueza de detalhes: o calor do meio-dia às duas da tarde parece mais mormacento, mais pesado, mais sufocante. A imagem da menina brincando de amamentar a boneca parece mais doce. A angústia da corrida até o mercado dos pais do amigo parece mais distante, mais cansativa. Mas, inevitavelmente, percebese a impossibilidade de falar sofrida pela menina, a bola peluda que não permite que diga o que supostamente aconteceu, o silêncio que torna o ocorrido falso, porque as palavras parecem não só evitar falar sobre, como também indicar que não aconteceu.

Ao descrever que a menina tinha vontade de gritar, mas não o fez, gritando "apenas para dentro de si" (p. 13), a narrativa demonstra que "por fora, um silêncio quieto, miudinho" (p.13) é o que se espera dela, apesar de, "tão pequena, com seu enorme e pesado segredo" (p.13). A menina não foge de um destino feminino, fadado a calar palavras, porque assim as ações abusivas vivenciadas por relacionamentos desse tipo, em nosso cotidiano, não existem. O segredo da essência feminina ainda perdura, muito maior que a morte pequena do marido, nebuloso desfecho, um outro possível sonho ruim. Silenciadas pela história e pela sociedade, pelos maridos e pelos comportamentos exigidos, as mulheres seguem usando as palavras escritas para poder falar o que as palavras do dia a dia se mostram impossibilitada pelos relacionamentos. Um resto de silencio ainda dominante e definidor das realidades femininas. Mas que a literatura de Valesca de Assis ousou revelar.

A narrativa de Valesca de Assis discute questões sociais, políticas e de gênero, sem, no entanto, tornar-se panfletária. É por isso que, além de feminista, a obra $A$ ponta do silêncio é feminina. Tão necessária ao momento em que vivemos porque revela um ambiente natural a uma enorme quantidade de mulheres. Mulheres que são levadas a calarem seus sentimentos em nome do marido, da família, da imagem cobrada por uma sociedade. Mulheres que negligenciam suas vidas em nome dos outros. Mas, também, mulheres que escolhem seus destinos em nome dos que amam, mesmo que os meios para tal não sejam justificáveis a todos em seus fins.

Em espaços da/na literatura de autoria feminina, essas relações têm sido indissociáveis e ampliam nossas experiências de leitura. Obras de produção feminina têm aberto um grande debate sobre o que a literatura pode revelar e o quanto essa revelação tem poder. As produções das mulheres escritoras evidenciam maior abertura e abrangência de vozes narrativas plurais e menos sistemáticas, mais democráticas e menos cerradas. Tendo as relações de espaços público e privado um grande definidor das circulações e não-circulações das mulheres no meio social, suas escritas não só abordam isso, como também fazem da escrita a transição desses espaços. Marga tem que pagar o preço pela negligência com o protagonismo da própria vida. Mas a escrita ainda possibilita que ela possa ousar ser quem é.

AMANDA OLIVEIRA PUCRS

Recebido: 10/04/2017 Aprovado: 29/11/2017 Contato: profeamandaoliveira@gmail.com (Amanda Oliveira) 